\title{
A Novel Method of Dyeing Nylon 6, 6 with Cold Brand Reactive Dyes and Assessment of its Fastness Properties
}

Sumithra $\mathbf{M}^{*}$ and Arasi D

Department of Costume Design and Fashion, PSG College of Arts and Science, Coimbatore, India

\begin{abstract}
Nylon is a synthetic fiber made from petroleum products which was developed as an alternative to silk. Nylon is valued for its light weight, incredible tensile strength, durability, and resistance to damage. It also takes dye easily, making the fabric available in a wide array of colours for consumers. Nylon has conventionally been dyed by using Acid dyes on a major extent. In this study Nylon 6,6 was dyed with commercial di-chlorotriazinyl reactive dyes .using $100 \%$ nylon woven fabric was taken for this study. Nylon fabric GSM was $50 \mathrm{~g} / \mathrm{m}^{2}$, EPI-20 and PPI-32. The pH was kept at 4 and the temperature was maintained at $98^{\circ} \mathrm{C}$, this temperature was used in subsequent experiments. The blue reactive dyes and acid dyes are used for dyeing and it was concluded as good to excellent fastness to washing and rubbing. And light fastness was almost equal for both reactive dyed and acid dye. In acid and reactive dyes Blue MR had good colour variation, good colour strength.
\end{abstract}

Keywords: Acid dyes; Blue color; Fastness properties; Nylon fabric, Reactive dyes

\section{Introduction}

Nylon is valued for its light weight, incredible tensile strength, durability, and resistance to damage. It also takes dye easily, making the fabric available in a wide array of colors for consumers [1].

Reactive dyes were commercially introduced over 40 years ago for cellulosic fibres and now form one of the most important dye classes for that fibre. The mechanisms of the interaction/reaction of reactive dyes with cellulosic fibres are well understood. The dye is first absorbed by the fibre and then reacts with it by either a substitution reaction for dyes containing, for example, a Monochlorotriazine (MCT) group or an addition reaction for dyes with a vinyl sulphone (VS) group [2].

Characteristically high wet fastness is derived from dyes thus covalently bound to the fibre. 1t is known that the reactive dyes developed for cellulosic fibres or for wool can be applied at the boil to nylon under weakly acidic conditions ( $\mathrm{pH}$ 4.0-6.0) and that covalent bonds form between the dye and the amino groups of nylon, without an alkaline fixation step. Since reactive dyes typically do not include heavy metals such as chromium, the characteristically high wet fastness of the dyes comes with the concomitant advantages of brightness and low environmental impact. Despite the obvious advantages, the commercialization of reactive dyes for nylon has not gained widespread success [3].

Acid dyes are highly water soluble, and have better light fastness than basic dyes. The textile acid dyes are effective for protein fibres such as silk, wool, nylon and modified acrylics. They contain sulphonic acid groups, which are usually present as sodium sulphonate salts. These increase solubility in water, and give the dye molecules a negative charge [4].

In an acidic solution, the $-\mathrm{NH}_{2}$ functionalities of the fibres are protonated to give a positive charge- $\mathrm{NH}^{3+}$. This charge interacts with the negative dye charge, allowing the formation of ionic interactions. As well as this, Van der Waals bonds, dipolar bonds and hydrogen bonds are formed between dye and fibre [5].
As a group, acid dyes can be divided into two sub-groups: acidleveling or acid-milling. These dyes are normally very complex in structure but have large aromatic molecules, having a sulphonyl or amino group which makes them soluble in water [6].

The main objectives of the study are as follows:

- To develop a new method to improve colour yield of di-chloro-triazinyl reactive dyes on Nylon.

- To improve fastness properties of di-chloro tri-azinyl reactive dyes on nylon.

- To compare fastness properties of reactive dyes and acid dyes on Nylon Fabrics.

- To develop a reactive dyeing technology for dyeing of Nylon that is applicable to industrial and domestic levels.

\section{Materials and Methods}

\section{Selection of fabric}

Four meters of bleached $100 \%$ woven nylon fabric of $50 \mathrm{~g} / \mathrm{m}^{2}, 20$ EPI, 32-PPI and Weight of the Fabric-82.82 g is selected for this Study. The fabric was purchased from komarapalayam, Salem.

\section{Methods}

The method adopted for this study is

*Corresponding author: Sumithra M, Department of Costume Design and Fashion, PSG College of Arts and Science, Coimbatore, India, Tel: +91-422430-33; E-mail: mithrasumi6@rediffmail.com

Received April 04, 2014; Accepted April 16, 2014; Published April 18, 2014

Citation: Sumithra M, Arasi D (2014) A Novel Method of Dyeing Nylon 6, 6 with Cold Brand Reactive Dyes and Assessment of its Fastness Properties. J Textile Sci Eng S2: 002. doi:10.4172/2165-8064.S2-002

Copyright: (C) 2014 Sumithra M, et al. This is an open-access article distributed under the terms of the Creative Commons Attribution License, which permits unrestricted use, distribution, and reproduction in any medium, provided the original author and source are credited. 


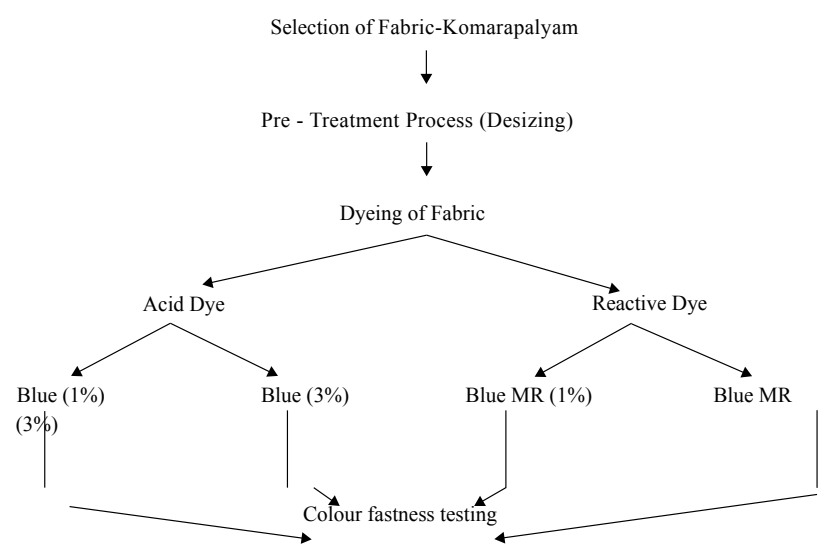

\section{Pre-Treatment}

Pre-treatment of Nylon fabric involves the usage of the following recipe for removal of these antistatic finishes as they hinder the dye absorption capability of the fabric. The ingredients used were:

\begin{tabular}{|l|l|}
\hline Soda ash & $2 \%$ \\
\hline Wetting oil & $0.5 \mathrm{gpl}$ \\
\hline Duration & $20 \mathrm{mins}$ \\
\hline Temperature & $70^{\circ} \mathrm{C}$ \\
\hline MLR & 20 \\
\hline
\end{tabular}

Soda ash and wetting oil were taken and added to the bath containing water. The fabric was introduced into the bath at $70^{\circ} \mathrm{C}$ and was treated for 20 minutes. Then it was taken out, rinsed with hot water and then with cold water. It was then squeezed and allowed to dry at room temperature.

The weight of fabric before pre-treatment was $82.82 \mathrm{~g}$ after which it was pre-treated and weight of fabric after pre-treatment was $82.30 \mathrm{~g}$ and hence, weight lost from the fabric was $00.52 \mathrm{~g}$.

The weight lost from the fabric refers to the amount of antistatic finish removed from the fabric. It accounts for about $0.63 \%$ of the total weight of the fabric.

\section{Dyeing}

Three different colours of cold brand reactive dyes of two shades for all blue colours were used for dyeing the fabric. The recipe for Nylon dyeing with cold brand reactive dyes is as follows:

\begin{tabular}{|l|l|}
\hline Acetic acid & $1 \%$ \\
\hline Glabour's salt & $10 \%$ \\
\hline Sodium acetate & $1 \%$ \\
\hline Blue MR Dyes & $1 \%$ \\
\hline Temperature & $50^{\circ} \mathrm{C}$ to $98^{\circ} \mathrm{C}$ \\
\hline Time & 10 minutes- 30 minutes \\
\hline
\end{tabular}

The Dyestuff, Acetic acid, Glabour's salt and Sodium Acetate are taken and added to the dye bath based on the recipe. The fabric is introduced into the bath at $50^{\circ} \mathrm{C}$ and treated for 10 minutes, then raised the temperature $70^{\circ} \mathrm{Cand}$ the fabric are treated for 20 minutes. The temperature is again raised to $98^{\circ} \mathrm{C}$ and the fabric is treated for 30 minutes. Dyed material is subjected to cold wash and then hot wash, Soaping with soap $5 \mathrm{gpl}$ and soda ash $2 \mathrm{gpl}$ is done at $50^{\circ} \mathrm{C}$ for 5 minutes. It is then cold washed and material is dried at room temperature.
The fastness properties to washing, rubbing are tested for the dyed fabrics under ISO test conditions as prescribed below.

- Wash fastness testing

IS:764-1979

- Rubbing fastness testing

IS:776-1956

- Light fastness testing

- $\Delta \mathrm{E}$ and Strength of Dyes

\section{AATCC 16E}

Macbeth 7000A Spectrophotometer

\section{Results and Discussions}

\section{Effect of temperature}

The exhaustion and fixation data obtained when different dyeing temperatures used. Since optimum dye exhaustion and dye fixation were achieved previously at $\mathrm{pH} 4$ which is necessary to achieve adequate substantively of the anionic dyes for the protonated amino end groups in the fibres, the effect of dyeing temperature was studied at this $\mathrm{pH}$ value. In the case of reactive dyes, due to low migrating power, careful control of dye exhaustion by means of temperature is demanded.

Higher dye exhaustion and fixation were obtained in the range of temperatures of $95-98^{\circ} \mathrm{C}$. This efficiency can be attributed to the higher kinetic energy of the dye molecules and their consequent greater migration power within the substrates. In addition, a higher extent of fibre swelling will have contributed to increased dye exhaustion. As maximum fixation efficiency was obtained around $98^{\circ} \mathrm{C}$, this temperature was used in subsequent experiments [6].

\section{Colourfastness properties}

The colourfastness to rubbing, washing and light of the alternative dyeing were generally good to excellent and the same as those achieved with the traditional dyeing formulation containing inorganic electrolyte and alkali. Such identical colour fastness results are encouraging.

\section{Comparison of colour fastness of reactive dyes and acid dyes}

Theoretically, reactive dyeing on nylon fibres should, by virtue of the covalent nature of the dye-fibre bond, display excellent fastness to washing without recourse to an aftertreatment. In this context, the aim of this experiment was to determine the level of fastness displayed by reactive dyeing on nylon substrates to extended washings and to compare this to that achieved using nylon fibres which had been dyed with acid dyes. The acids dyeing having the similar color strength with reactive dyeing were prepared using colour matching system. Thus, these samples are appropriate for the comparison of wash tests.

The colour strength of the acid dyeing decreased with increasing number of washes and that dye desorption from the dyed samples occurred progressively as the number of washes increased. It is evident that for each of the three reactive dyes, the extent of dye loss that occurred during repeated washings was very low and the shade of the dyeing was little changed. The considerable difference in washdown observed between the reactive dyeing and the acid dyeing can be attributed to the difference in the nature of dye-fibre interaction, namely covalent, in the case of the reactive dyes and non-covalent in the case of the acid dyes. The table show that the reactive dyeing displayed very good fastness properties to washing in terms of shade change and that very little staining to the adjacent multifiber strip occurred. This result can be also attributed to the nature of the covalent bond characteristics.

Table 1 shows the colourfastness of Nylon fabrics with Orange M2R and Acid Orange with $1 \%$ shade, thewashing colour change in Reactive dyed Nylon was equal to that of Acid dyed Nylon fabric. Staining on 
Citation: Sumithra M, Arasi D (2014) A Novel Method of Dyeing Nylon 6, 6 with Cold Brand Reactive Dyes and Assessment of its Fastness Properties. J Textile Sci Eng S2: 002. doi:10.4172/2165-8064.S2-002

\begin{tabular}{|l|c|c|}
\hline Sample number & Sample 1 & Sample 1 \\
\hline Sample particulars & Nylon reactive dyed & Nylon acid dyed \\
\hline Dye particulars & Blue m2r-1\% & Acid blue-1\% \\
\hline Colour fastness to washing & & \\
\hline Change in colour & 03-Apr & 03-Apr \\
\hline Staining on wool & 04-May & 4 \\
\hline Staining on acrylic & 04-May & 5 \\
\hline Staining on polyester & 04-May & 5 \\
\hline Staining on nylon & 4 & $03-\mathrm{Apr}$ \\
\hline Staining on cotton & 4 & 4 \\
\hline Staining on acetate & 04-May & 4 \\
\hline Colour fastness to rubbing & & \\
\hline Dry rubbing (staining) & 04-May & $04-\mathrm{May}$ \\
\hline Wet rubbing (staining) & 4 & 4 \\
\hline Colour fastness to light Light-fading & $04-M a y$ & $5-6$ \\
\hline (10 hours) & & $1,00,310.23$ \\
\hline Strength of dyes & Blue mr (3\% ) & \\
\hline
\end{tabular}

Table 1: Colour fastness of Nylon fabrics dyed with blue M2R and Acid blue.

Wool, Acrylic, Polyester, Nylon, Cotton and Acetate was almost equal in both the cases.

The fastness to dry and wet rubbing was also equal in both the cases. The fastness to $10 \mathrm{hrs}$ of light exposure was better in case of Acid dyed Nylon fabrics. Among the dyes used for dyeing, Blue MR had good colour strength.

\section{Conclusion}

The blue MRdyes used for dyeing it has well to excellent fastness to washing and rubbing. The Light fastness was good for all the three dyes used for dyeing. The fastness results depicted the image that the fastness was almost equal for both Reactive dyed and acid dyed Nylon fabrics.Blue MR had good colour strength, when compare to acid dyes. In future, this dyeing process can be done by varying the $\mathrm{pH} 5-6$, temperature $-50^{\circ} \mathrm{C}$ to $98^{\circ} \mathrm{C}$ and salt concentration 12 to $15 \%$.

\section{References}

1. Burkinshaw SM, Young AS, Chevli SN (2000) The fastness, to repeated washing, of reactive dyes and pre-metallised acid dyes on nylon 6,6. Dyes and Pigments 45: 43-49.

2. Burkinshaw SM, Chevli SN, Marfell DJ (2000) Printing of nylon 6,6 with reactive dyes; Part I: preliminary studies. Dyes and Pigments 45: 235-242.

3. Burkinshaw SM, Young AS, Bide MJ (2001) The application of hetero bifunctional reactive dyes to nylon 6,6; process modifications to achieve high efficiencies. Dyes and Pigments 48: 245-251.

4. Soleimani GA, Taylor JA (2006) Dyeing of nylon with reactive dyes. Part 1. The effect of changes in dye structure on the dyeing of nylon with reactive dyes. Dyes and Pigments 68: 109-117.

5. Soleimani GA, Taylor JA (2006) Dyeing of nylon with reactive dyes. Part 2 . The effect of changes in level of dye sulphonation on the dyeing of nylon with reactive dyes. Dyes and Pigments 68: 119-127.

6. Soleimani GA, Taylor JA (2008) Dyeing of nylon with reactive dyes. Part 3 Cationic reactive dyes for nylon. Dyes and Pigments 76: 610-623. 